\title{
Las campañas a los puertos intermedios y la fase «peruana» de la independencia
}

\author{
por \\ Natalia Sobrevilla Perea \\ University of Kent
}

\begin{abstract}
A pesar de que la historiografía peruana ha dejado de lado el estudio de las dos campanas conocidas como campañas a los puertos intermedios, localizados entre el Callao y Valparaíso, dichas campañas constituyen uno de los momentos más importantes de la llamada fase "peruana» de la independencia, aunque ambas incursiones terminaran en derrotas. A pesar de ello, las campañas merecen recibir más atención académica porque fueron las que tuvieron una mayor movilización por parte de los peruanos, porque de haber tenido éxito habrian dado lugar en esta zona del continente a estados muy diferentes de los que existen actualmente y porque los problemas que surgieron en estas campañas mostraron las dificultades a las que se enfrentarían los nuevos estados emergentes.

Palabras Clave: guerras de independencia; campañas a puertos intermedios; independencia peruana.
\end{abstract}

Cómo citar este artículo / Citation: Sobrevilla Perea, Natalia, "Las campañas a los puertos intermedios y la fase «peruana» de la independencia", Revista de Indias, LXXXI/281 (Madrid, 2021): 115-141. https://doi.org/10.3989/revindias.2021.004.

Una de las preocupaciones principales de la historiografía sobre la independencia en el Perú ha sido si esta fue el resultado de los esfuerzos de los mismos peruanos o si se debió más bien a la intervención de fuerzas extranjeras $^{2}$. Considero que se trata de dos versiones de una misma pregunta, que

1 N.Sobrevilla@kent.ac.uk, ORCID iD: https://orcid.org/0000-0001-9592-7551

${ }^{2}$ La visión que postula que la independencia se debió a esfuerzos peruanos se encuentra en De la Puente y Candamo, 2013, mientras que quienes presentan el de la conocida como la «independencia concedida» son Bonilla y Spalding, 1971. 
nace de una perspectiva que ve ya, en el momento de la ruptura con la corona española, la clara existencia de una nación «peruana» que buscaba obtener su libertad, o no ${ }^{3}$. Si bien el Virreinato del Perú fue una realidad desde inicios del siglo dieciséis, y en el tiempo transcurrido quienes habitaban en él habían desarrollado una cierta identidad vinculada al lugar de origen, me parece que hablar de una nacionalidad peruana antes de la creación de la república del mismo nombre es prematuro. Hasta inicios del siglo diecinueve los sentimientos de pertenencia estaban ligados a espacios más acotados, fueran estos las ciudades, de donde se era vecino, o en algunos casos la provincia de residencia, conocidas entonces como «patria» ${ }^{4}$. Fue justamente durante el largo y complejo proceso de independencia cuando se fueron afianzando las identidades, y creando nuevos estados desde donde se comenzó realmente a desarrollar la idea de nación que hoy conocemos. Es por ello que juzgar si los peruanos lucharon por su independencia o no, resulta en gran medida anacrónico. El fin de la relación con la corona española y la creación de un nuevo estado que con el tiempo se convirtió en la República Peruana fueron parte de un proceso global y regional que solo puede comprenderse al estudiar una serie de eventos conectados, en los que participaron no solo personas nacidas en diferentes provincias del Virreinato del Perú, si no también, en muchos otros lugares del continente, e incluso de Europa.

De la misma manera como la historiografía ha buscado entender la independencia en clave nacionalista, poniendo a los peruanos como autores de su libertad, principalmente resaltando el papel de los «precursores», las conmemoraciones se han centrado casi exclusivamente en la proclamación de independencia dada por San Martín en Lima el 28 de julio de 1821, y en algunos casos en las batallas de Junín y Ayacucho de 1824. Si bien esto ha contribuido a que el énfasis se ponga en los actores externos, en algunos momentos, en particular durante las celebraciones del sesquicentenario, durante el último gobierno militar, se realzaron las figuras de Túpac Amaru y de los ideólogos de la independencia, buscando de esta manera resaltar la participación «peruana» ${ }^{5}$. Estas perspectivas han producido que las campañas conocidas como campañas a los puertos intermedios se encuentren entre los episodios

\footnotetext{
3 Sobrevilla Perea, 2015a.

${ }^{4}$ Sobrevilla Perea, 2012a.

5 Basta hacer una revisión somera a los tomos de la Colección Documental de la Independencia del Perú publicada en 80 tomos y volúmenes entre 1971 y 1976 por la Comisión Nacional del Sesquicentenario de la Independencia del Perú para ver el interés que despertaron estos temas durante el sesquicentenario.
} 
menos discutidos y celebrados del proceso de independencia peruana. Dado que las incursiones a los puertos entre el Callao y Valparaíso terminaron en derrotas (y que tras la primera se vivió el primer golpe de estado en el Perú y durante la segunda el gobierno independiente se dividió en dos y Lima fue tomada una vez más por los realistas) es comprensible que no sean momentos que se recuerden con mucho entusiasmo. Considero, sin embargo, que es muy importante destacar estas campañas por tres motivos. Primero porque estas movilizaciones contaron con una mayor participación de las personas nacidas en el Perú. Segundo, porque si las movilizaciones hubiesen tenido éxito, la forma y composición de los nuevos estados en la región hubiera sido muy diferentes. Tercero, porque los problemas que surgieron en las campañas muestran claramente las dificultades y tensiones a las que se enfrentaron los nuevos estados emergentes.

Para poder desarrollar una mejor compresión del proceso de independencia peruano, así como de las regiones andinas, el presente artículo se divide en cuatro partes. La primera se concentra en los antecedentes que llevaron al desarrollo de estas incursiones, así como al análisis de los actores principales y sus intereses. La segunda se enfoca en la primera campaña a intermedios, detallando como se llevó a cabo y las consecuencias de su fracaso. La tercera sección estudia la segunda incursión, desde sus inicios promisorios, las dificultades que enfrentó en su desarrollo y las divisiones que resultaron de la derrota. Una sección final analiza cómo las campañas tuvieron impacto en la región a corto, mediano y largo plazo, así como de qué manera influyeron en la formación de las nuevas repúblicas de los Andes. Es importante definir el área andina, ya que al ver el mapa de la colonización española en Sudamérica queda claro que la cordillera de Los Andes, desde Venezuela hasta Tierra del Fuego, sirvió como espina dorsal a la penetración española en la región. En este periodo ninguno de los espacios coloniales se había expandido a los espacios amazónicos y, por tanto, las nuevas repúblicas estuvieron limitadas a las regiones andinas, así como a las planicies que se formaron alrededor de los ríos que nacen en las cordilleras, atravesando valles y explanadas hasta llegar a la costa. La historia de estas repúblicas, forjadas al calor de la guerra, estuvo estrechamente conectada, y para entender los procesos que llevaron a su existencia es preciso ver la forma en que interactuaron las realidades de espacios tan dilatados 6 .

${ }^{6}$ Sobre la utilidad de la historia conectada para entender este tipo de procesos véase Subrahmanyam, 2004; 2009. 


\section{AnteCedentes y Actores}

Cuando se dieron las campañas de intermedios en 1823, la mayoría de los espacios del continente americano ya se habían independizado. México y Brasil eran imperios, Chile y Colombia repúblicas, mientras que las provincias del Río de la Plata luchaban por quién debía tener primacía: la Liga de los Pueblos Libres, la Provincia de Buenos Aires o algún otro arreglo entre provincias, o lo que Marcela Ternavasio ha llamado las Repúblicas Provinciales Independientes $^{7}$. El Perú se encontraba dividido entre una república que abarcaba desde Lima hasta el norte y un Virreinato que aún se regía por la Constitución de Cádiz, con capital en el Cuzco ${ }^{8}$. La guerra había sido una fuerza transformadora tanto en el norte como en el sur del continente encumbrando a generales tan distintos como Simón Bolívar y José de San Martín. Ambos, que habían logrado ascender gracias a su capacidades de liderazgo y organización, y que para los primeros años de la década de 1820 habían llevado a cabo proezas similares atravesando los Andes con sus ejércitos y derrotando a quienes defendían al rey en las batallas de Chacabuco (1817), Maipú (1818), Boyacá (1819) y Carabobo $(1821)^{9}$. Después de las dos grandes victorias de San Martín al sur del continente se estableció la República de Chile, mientras que Bolívar logró la creación de la República de Colombia al conseguir agregar los territorios de la Capitanía General de Venezuela a los del Virreinato del Nuevo Reino de Granada en el Congreso de Angostura. Si bien la historiografía ha tendido a llamar a este estado federado La Gran Colombia para diferenciarlo de la actual República de Colombia, este no fue el nombre que se usó en su momento. Este trabajo hará por ende uso del término República de Colombia para designar al estado creado en 1819 en Angostura y ratificado en 1821 con la Constitución de Cúcuta ${ }^{10}$.

El término Argentina era usado en el periodo para designar a las personas nacidas en el Río de la Plata, pero a inicios de la década de 1820 las Provincias de esa región se hallaban disgregadas y no existía un estado «argentino» como tal. Paraguay había tomado su propio rumbo, desde muy temprano, mientras que Buenos Aires había buscado aglutinar el poder y establecer un acuerdo constitucional, pero había fallado en sus intentos. La Liga de los Pueblos Libres, bajo la dirección de Artigas, por otro lado, unía

\footnotetext{
${ }^{7}$ Marcela Ternavasio, "Intervención en el «Congreso del Trienio Liberal», celebrado en Zaragoza el 6 de noviembre de 2019", inédita.

8 Sobre el gobierno virreinal en el Cuzco véase Sala i Vila, 2011.

9 Existen numerosas biografías de ambos líderes, pero las de Lynch, 2006; 2009 los compara.

${ }^{10}$ Sobre esta constitución véase Sosa Abela, 2009.
} 
a algunas de las provincias del litoral, así como la Provincia Oriental, pero tampoco logró establecer un gobierno exitoso y desde 1817 se había convertido en la Provincia Cisplatina bajo el control del Imperio de Brasil. Las provincias andinas, de Tucumán, Salta y Jujuy se encontraron constantemente en guerra, amenazadas por las tropas realistas desde la Audiencia de Charcas hasta $1822^{11}$. En 1816 José de San Martín había organizado y armado un gran ejército en la Provincia de Cuyo, en la ciudad de Mendoza, compuesto de algunos batallones de negros venidos desde Buenos Aires, paisanos de la provincia o sus aledañas y un gran número de emigrados de Chile que habían huido del ejército de reconquista enviado desde Lima ${ }^{12}$. Una vez que con las victorias de 1817 y 1818 , se consolidó la independencia chilena, quedó muy claro que el próximo objetivo de quienes lideraban ese nuevo país, entre ellos el hijo ilegitimo de un antiguo virrey, Bernardo O'Higgings, era la liberación del Perú. Los chilenos, que ya habían vivido la experiencia de ser invadidos por tropas limeñas, invirtieron en crear una armada y financiaron la expedición de San Martín que había quedado sin el apoyo de Buenos Aires y a quienes sus hombres pusieron al mando del Ejército de Los Andes con la misión de liberar al Perú ${ }^{13}$.

En el virreinato peruano la guerra había llevado a experiencias muy diversas y fue así que lo vivido en las regiones norte fue diametralmente opuesto a lo que sucedió en el sur. Las provincias de Cuzco, Arequipa y Puno movilizaron tropas desde 1809 para enfrentarse a las incursiones organizadas por las Juntas creadas en La Paz y Buenos Aires, e incluso habían visto un levantamiento importante contra la corona en 1814. Mientras que todo esto sucedía, las provincias del norte peruano se habían mantenido en paz organizando e uniformando sus milicias para paradas de domingo ${ }^{14}$. En la capital, el virrey Abascal enfrentó a una serie de agitadores, entre los cuales se encontraba el noble limeño José de la Riva Agüero célebre por haber escrito un tratado que

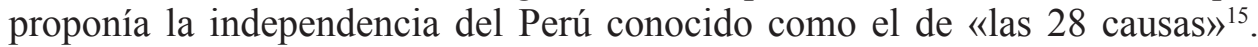
Riva Agüero había servido casi un año de cárcel, pero gracias a sus contactos había logrado salir en libertad para conspirar durante el bloqueo naval a la costa peruana de 1819 por parte de la armada Chilena comandada por el

11 Sara Emilia Mata, "La herencia de la guerra Salta (Argentina) 1821-1831”, Nuevos Mundos, Mundos Nuevos, en línea, 13 de julio 2012, consultado 17 julio 2020.

12 Para conocer más sobre este ejército véase Ossa Santa Cruz, 2014.

13 Rabinovich, 2012: 212.

14 Sobrevilla Perea, 2012a.

15 Hernández García, 2019. 
aristócrata escocés Thomas Cochrane ${ }^{16}$. Continuó haciéndolo hasta la llegada de San Martín en septiembre de 1820 cuando comenzó la primera campaña bélica en el Perú, liderada por Juan Antonio Álvarez de Arenales, un peninsular que había luchado por la Junta de Buenos Aires en la Audiencia de Charcas y que se había encumbrado junto a San Martín. Tras el desembarco en Pisco, Arenales tomó el camino de la sierra declarando independencia en las ciudades de Ica, Ayacucho, Huancayo y Tarma hasta vencer en la Batalla del Cerro de Pasco en diciembre de $1820^{17}$. Ese mismo mes la provincia de Trujillo en el norte del Perú se declaró independiente, bajo el mando de otro noble limeño, José Bernardo de Tagle, Marqués de Torre Tagle. San Martín fue muy cercano a él llegando incluso a ser padrino de uno de sus hijos, conectándose de esta manera a la nobleza limeña ${ }^{18}$. San Martín había logrado, entonces, la independencia de una parte importante del virreinato peruano siguiendo su designio principal, confiar en el apoyo de los mismos peruanos.

El inicio del desmoronamiento del virreinato peruano, sin embargo, había comenzado antes con la llegada de las noticias de la reimplantación de la Constitución de Cádiz. El virrey Joaquín de la Pezuela, veterano de las campañas militares en la Audiencia de Charcas de 1813 a 1816, demoró la jura de la carta, y su posición a cargo del poder en Lima era precaria ${ }^{19}$. Los oficiales llegados a América después de la derrota de Napoleón desconfiaban de su criterio y de su cercanía a los criollos. Entre ellos el más encumbrado era el General José de la Serna, a cargo de los destacamentos militares en el Sur del Perú y la Audiencia de Charcas, y quien en 1819 había forzado al virrey a convocar una Junta de Guerra para responder al bloqueo naval ${ }^{20}$. La rivalidad entre estos dos grupos se ha tendido a ver ligada a la cercanía de los recién llegados al liberalismo, esto hasta cierta medida ha sido así por la demora de Pezuela en hacer jurar la Carta de $1812^{21}$. Pero las diferencias no se limitaban a su relación con las nuevas autoridades encargadas del poder en la Península, o con el retorno de la constitución sino que incluían además como debía llevarse a cabo la guerra, así como llevar a cabo las negociaciones de paz ordenadas por el Rey, en el contexto del Trienio Liberal ${ }^{22}$.

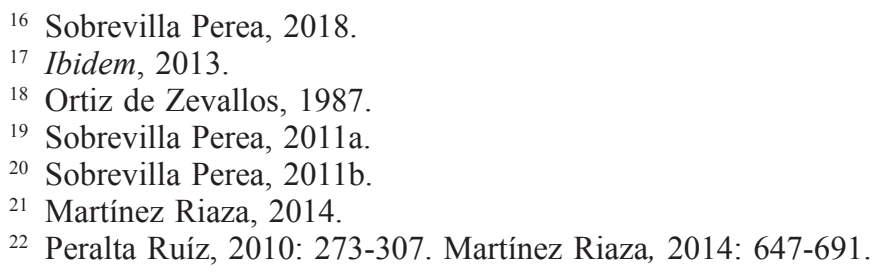


La situación llegó a tal punto que el 29 de enero de 1821, inspirados por Rafael Riego, diecinueve oficiales se pronunciaron en el campamento militar de Aznapuquio y depusieron al virrey Pezuela en favor del General José de la Serna ${ }^{23}$. A pesar de haber criticado la política de conciliación de su antecesor, el nuevo virrey entró en tratativas con San Martín, pero al fallar estas también, y ante la cada vez más precaria situación, los defensores de la corona abandonaron la capital y establecieron un nuevo centro del virreinato en el $\mathrm{Cuzco}^{24}$. Con la ciudad de Lima desguarecida los miembros de la elite le imploraron a San Martín que la tomara y declarara la independencia, cosa que hizo el 15 de julio y que luego ratificó con una Proclamación pública el día $28^{25}$. Con esto el Perú quedó decididamente dividido entre un estado independiente en el norte y el virreinato constitucional en el sur. A pesar de que los peruanos que estaban del lado de San Martín eran quienes menos experiencia bélica tenían, esto se fue subsanando con el progresivo cambio de bando de quienes habían luchado por la corona por más de una década y habían aprendido a llevar a cabo la guerra en el sur andino. Criollos y mestizos como Domingo Tristán, Agustín Gamarra, Andrés de Santa Cruz y José de La Mar, todos ellos actores claves en las campañas a los puertos intermedios.

El avance de los ejércitos de San Martín sobre el Perú convenció a estos hombres con más de una década al servicio a la corona de cambiar de bando. Algunos como el arequipeño Domingo Tristán, hermano de Pio, el capitulado en la Batalla de Salta de 1812, había tenido momentos de duda en su servicio al rey, pero se había mantenido en el ejército hasta que la llegada de los nuevos oficiales peninsulares fue poniendo cada vez más en entredicho su idoneidad para servir y sus posibilidades de ascender ${ }^{26}$. Similar fue la experiencia del cuzqueño Agustín Gamarra quien se enroló como cadete en 1809 desarrollando su carrera bajo la dirección de José Manuel de Goyeneche y Pezuela, pero cuyas opciones se fueron reduciendo bajo la comandancia de La Serna. Gamarra optó, una vez que San Martín estuvo en el Perú, por abandonar al virrey diciéndole que iba en busca de más hombres a Puno ${ }^{27}$. Los casos tanto de Santa Cruz y La Mar fueron diferentes ya que su cambio de bando fue el resultado de una derrota. Santa Cruz, un mestizo paceño, alférez en el ejérci-

23 "Manifiesto del virrey del Perú Joaquín de la Pezuela sobre su separación del mando", Colección Documental de la Independencia del Perú, 1971-76, tomo XXVI, vol. 3: 267-505. Véase también Refutación que hace el Mariscal..., 1895.

${ }^{24}$ Sobrevilla Perea, 2011b: 480.

25 Ortemberg, 2014.

26 Sobrevilla Perea, 2012a.

27 Pezuela, 1947. 
to del sur del Perú desde 1809, fue capturado dos veces. Después de escapar de la prisión de las Bruscas a las afueras de Buenos Aires en 1819 volvió hasta el Perú, y se re-enroló en el ejército, pero tras la derrota en la Batalla de Cerro de Pasco a fines de 1820 se decidió por la independencia ${ }^{28}$. El General cuencano, José de La Mar había hecho una larga carrera en la Península cuando volvió a América, y quedó al mando del Fuerte del Real Felipe en el Callao en el momento que las tropas realistas abandonaron Lima. Dos meses más tarde sin agua, ni comida y sin la posibilidad de ser abastecido por los hombres del General Canterac, La Mar se rindió ante San Martín, entregando el fuerte en septiembre de 1821.

Todos fueron recibidos con los brazos abiertos y se les reconoció su mismo grado. San Martín estaba convencido que dimisiones como estas harían la situación de los realistas en el sur del Perú insostenible. Pero esto no sucedió y tras más de seis meses de tensa calma en Lima, donde toda la energía se consumía en debatir si el Perú debía ser una monarquía o una república se hicieron esfuerzos por desarrollar una campaña militar. En febrero de 1822, Tristán y Gamarra comandaron mil setecientos hombres al sur de Lima a la provincia de Ica, buscando enfrentarse con los realistas de Arequipa y Ayacucho $^{29}$. La Batalla de Macacona, dada en abril, resultó en un estrepitoso fracaso por la falta de información y preparación ya que ni Tristan, ni Gamarra esperaban enfrentar unas fuerzas de más de 4000 hombres. Mientras que el General Canterac se encontraba en la sierra central, listo para descender sobre Lima ante cualquier oportunidad ${ }^{30}$. La Batalla resultó en la absoluta dispersión del ejército libertador del sur y de la suspensión de funciones de Gamarra y Tristán. A pesar de la derrota esta incursión fue importante para entender como maniobraba el ejército realista, así como su velocidad.

La segunda iniciativa que organizó San Martín fue el envío de tropas para apoyar a Sucre y a Bolívar en la campaña sobre Quito. La Mar había ido primero para promover la independencia por medio de la prensa en su Cuenca natal, mientras que un contingente de 1300 hombres llegó desde Lima, liderados por Santa Cruz, ante la negativa de Arenales de servir bajo las órdenes de Sucre, un hombre mucho más joven ${ }^{31}$. En febrero 1822, los refuerzos

${ }^{28}$ Sobrevilla Perea, 2015b.

29 Colección Documental de la Independencia del Perú, 1971-76, Tomo VI Asuntos Militares, vol. 6, "Anexo del año 1822 sobre el Estado Militar y cuestiones conexas".

${ }^{30}$ Los juicios a Tristán y a Gamarra de mayo de 1822, muestran la frustración que resulto de esta campaña, Colección Documental de la Independencia del Perú, 1971-76, tomo VI, vol. 6: 20-45.

31 Sobrevilla Perea, 2015b. 
llegaron al sur de Quito, desde la Provincia de Trujillo cuyos habitantes habían invertido unos 20.000 pesos para armarlos y vestirlos. Sucre contaba solamente con 1.700 efectivos, por lo tanto la victoria final de Pichincha se debió al trabajo conjunto con quienes habían venido del Perú. Sucre mismo lo reconoció en el bando que emitió en Riobamba tras un primer enfrentamiento, cuando exhortó:

Argentinos! Vuestra sangre derramada sobre la tierra de Colombia es un monumento que señalará siempre en le república vuestra bravura heroica y vuestras virtudes militares.

Peruanos! Vuestros sacrificios excitan cada vez más nuestra gratitud: ellos van a enjuagar el llanto de una parte de la familia colombiana que ha fiado su existencia a vuestro valor, y a vuestra generosidad ${ }^{32}$.

Un mes más tarde vencieron en la Batalla de Pinchincha y tras la capitulación después de esta, los realistas fueron expulsados permanentemente del norte del continente, mientras que en el sur, en el corazón de los Andes un Virreinato regido por la Constitución de Cádiz y bajo el mando de los veteranos de las guerras napoleónicas, dominaba casi todos los espacios desde Huancayo hasta Jujuy.

Bolívar que había permanecido en Pasto donde el apoyo a su causa no era tan claro, concertó con San Martín una reunión en la ciudad de Guayaquil para discutir la estrategia con la que enfrentar a los últimos realistas en el continente. Si bien no queda registro de qué se discutió en ese encuentro dado el 22 de julio de 1822, quedaba claro aún antes de su inicio que San Martín tenía mucho menos que ofrecer, a pesar de lo crucial que había sido su apoyo en la campaña sobre Quito. Bolívar se encontraba triunfante, habiendo consolidado la República de Colombia con la que soñaba. San Martín estaba lejos de sus bases de apoyo, y contaba cada vez menos con los chilenos. La situación en Lima era volátil ya que casi un año después de la proclamación de la independencia peruana se veía muy poco progreso en cuanto al fin de la guerra ${ }^{33}$. Bolívar se comprometió a ir al Perú en cuanto el Congreso Colombiano le diera permiso y San Martín que había gobernado en Lima con el título de protector y con un Reglamento provisorio volvió al Perú a instalar el primer Congreso y partió al exilio. Durante la ausencia de San Martín la población de Lima se había levantado en contra de Bernardo de Monteagudo quien se había quedado encargado, mostrando tanto el hartazgo con su régi-

32 Antonio José de Sucre, Riobamba, 22 abril 1822, en Colección Documental de la Independencia del Perú, 1971-76, tomo VI, vol. 6: 49.

33 Sobrevilla Perea, 2015b: 84-85. 
men, como al optimismo para enfrentar el futuro sin su apoyo ${ }^{34}$. El primer ejecutivo encargado del poder fue un triunvirato presidido por José de la Mar y compuesto por el comerciante salteño Felipe Antonio Alvarado, hermano de un General venido con San Martín y el noble limeño Manuel Salazar y Baquijano, Conde de la Vista Florida. Fueron ellos los encargados de organizar la primera campaña a los puertos intermedios.

\section{LA PRIMERA CAMPAÑA A LOS PUERTOS INTERMEDIOS}

Los planes para la campaña habían comenzado en 1822 con la idea de atacar a Pedro Antonio de Olañeta, que era el comandante localizado más al sur, y quien tenía 1.400 hombres dispersos en el departamento de Potosí. Después de la derrota de Macacona en que se comprobó la velocidad de Valdés, Canterac y Carratalá para subir y bajar de la sierra se decidió navegar mucho más al sur, hasta el Puerto de Iquique. Pero los planes se dilataron y la expedición no estuvo lista para marchar hasta después de la instalación del Congreso en septiembre de 1822. El General inglés William Miller, jefe del batallón peruano de la guardia, detalla cómo después del juramento de fidelidad a las nuevas autoridades, él llevó a su cuerpo al Callao en parada para preparar su embarque ${ }^{35}$. La campaña estaba encabezada por el General Rudencindo Alvarado, hermano del comerciante que formaba parte del triunvirato y que se había distinguido en las campañas sobre la Audiencia de Charcas y Chile ${ }^{36}$. Para cubrir las necesidades económicas de la expedición se impuso una contribución forzosa de cuatrocientos mil duros al comercio de Lima. Los británicos, que debían afrontar la mitad, se negaron a pagar, pero después de una tensa negociación en la que intervino el Capitán de la armada británica en el Callao, accedieron a contribuir con unos dos mil duros de manera voluntaria ${ }^{37}$. Para octubre salieron seis embarcaciones con 5.850 hombres, conformados por 2.000 peruanos al mando de Miller, 1.600 rioplatenses y 2.250 chilenos. Luego de una primera parada en Iquique donde un destacamento se quedó, la mayoría navegó a Arica ${ }^{38}$.

Mientras este gran contingente se concentró en el sur, en Lima quedaron unos 4.000 hombres, 1.200 de ellos colombianos. Hasta cierto punto la premura para que la expedición dejara Lima fue para limitar el descontento de las

\footnotetext{
34 Sobre el tema véase Mc Evoy, 1996.

${ }^{5}$ Miller, 1829: 2.

${ }^{36}$ Paz Soldán, 1868: 21.

37 Miller, 1829: 3.

38 Ibidem: 5.
} 
tropas venidas del Río de la Plata y Chile, que querían recibir su paga ${ }^{39}$. Arenales preparó una campaña con los hombres que quedaron en la capital encargada de presionar a Canterac en la sierra central. Para enero de 1823 estas fuerzas se encontraban en Huancayo, pero dado que su situación económica era muy precaria, Arenales pidió permiso para llevar sus fuerzas hasta la ciudad minera de Cerro de Pasco con la esperanza de conseguir más recursos. Tanto él como su lugarteniente Andrés de Santa Cruz conocían bien la zona ya que se habían enfrentado en una Batalla en ese mismo lugar, tan solo dos años antes $^{40}$. La sierra al este de la capital era además el centro de operaciones de un gran número de montoneras y milicias que apoyaban al gobierno independiente y buscaban dificultar el movimiento de los defensores de la corona ${ }^{41}$. Los pueblos de Canta, Oyón e incluso el mismo Cerro de Pasco a menudo se encontraban en manos de quienes reconocían al gobierno independiente de Lima. A pesar de ello el triunvirato no le permitió a Arenales buscar recursos en la región, instruyéndole en vez a esperar al General colombiano Paz del Castillo quien según el historiador Manuel Felipe Paz Soldán se rehusaba a servir a menos que fuera bajo la dirección de un jefe peruano ${ }^{42}$. Al no ser eso posible, decidió abandonar Lima con rumbo a Guayaquil para asegurarse que el puerto que había sido tradicionalmente parte del virreinato peruano se anexara a Colombia. A pesar que esto era algo que La Mar buscaba evitar, Santa Cruz, responsabilizó al triunvirato, y en particular al General cuencano por el fracaso de su incursión, ya que se vio obligado a volver a la ciudad de Lima ${ }^{43}$.

En la sierra central Canterac tenía unos 5000 hombres mientras que más al sur, sobre los puertos intermedios, el General Valdés comandaba a unos 3.000. En diciembre de 1822, la mayoría de las tropas independentistas desembarcaron en Arica después de una difícil navegación que tuvo como consecuencia la perdida de algunos hombres que tuvieron que volver a Lima a reparar averías. Unos ciento cincuenta se quedaron en Iquique para subir por Tarapacá con dirección a Potosí y en el campamento principal se reunieron unos 3.000 hombres. Miller describe al contingente a su cargo como tres cuartas parte indígenas quechua-hablantes que en su mayoría no sabían más castellano que las palabras de mando que se les había enseñado para seguir las ordenanzas españolas. Eran, según el inglés:

\footnotetext{
39 Rabinovich, 2012: 231.

40 Sobrevilla Perea, 2015b: 86.

41 "Guerrillas y montoneras durante la independencia" en Colección Documental de la Independencia del Perú, 1971-76, tomo 5, vol. 3.

42 Paz Soldán, 1868: 22.

43 Sobrevilla Perea, 2015b: 86.
} 
... de poca estatura, robustos y sin barbas, de color moreno y cutis reluciente. El resto de la gente eran mulatos, y unos cuantos criollos blancos que eran generalmente sargentos ${ }^{44}$.

Miller notó además la aptitud musical de quienes estaban encargados de la banda, que tocaban la música para que los indios cantaran sus yaravíes, así como la música que le gustaba a los limeños mulatos y blancos; menciona también la cercanía y familiaridad entre los oficiales y los soldados, algo que no se conocía en Europa. En sus memorias, Miller es muy crítico con la falta de acción de Alvarado quien no se decidía por qué camino tomar y tenía a sus hombres entre los valles de Arica y Azapa sin dar pasos para la preparación para el ataque.

Casi tres años antes, en mayo de 1820 Miller había combatido con sus marines en los valles de Moquegua, Torata y Locumba y por ende conocía bien el terreno ${ }^{45}$. Cuando fue consultado por Alvarado, el coronel inglés le hizo saber que se debía actuar lo más pronto posible, ya que la inacción e indecisión eran peligrosas. Miller fue inmediatamente enviado a los puertos de Arequipa, con el objetivo de dividir a los realistas. Valdés que había seguido el avance de las tropas enemigas, se encontraba en Tacna con unos 3000 hombres organizados en «dos compañías de infantería montadas en mulas, cinco escuadrones y dos piezas de artillería» ${ }^{46}$. A pesar de que se corrió la voz que el destino de Miller era Tarapacá, sus enemigos tenían muy en claro que se había embarcado a Quilca y el General Carratalá fue enviado a detener sus avances. La costa de esta parte del sur de Perú se caracteriza por estar cubierta de desiertos extremadamente áridos donde solo se puede sobrevivir en los estrechos valles, algunos de los cuales están separados por pocas leguas de distancia y que suben hasta el altiplano. La estrategia de los realistas fue dirigir a su enemigo a los valles de Moquegua y Torata donde la comunicación es aún más difícil por estar rodeados de desiertos y montañas empinadas que resaltan aún más su estrechez, y donde una vez que se llega a ellos por la costa o por la sierra no es posible comunicarse con facilidad con los otros valles. Valdés se retiró de Tacna, dejando a Alvarado tomar la ciudad y se dirigió a Torata. Mientras tanto Canterac, que había dejado los valles al este de Lima hacía semanas se desplazó desde Puno con un par batallones de caballería para apoyar la defensa de Valdés. Olañeta para entonces ya había derrotado al destacamento que se dirigía a Potosí desde Tarapacá.

El conocimiento del terreno, así como los años de preparación les daban a los realistas una serie de ventajas, ya que no solamente contaban con tropas bien

\footnotetext{
${ }^{44}$ Miller, 1829: 9.

${ }^{45}$ García Camba, 1916: 535.

${ }^{46}$ Ibidem, 1846, vol. II: 30.
} 
entrenadas y abastecidas, sino que llevaban más de una década utilizando la provincia de Arequipa como base de operaciones ${ }^{47}$. Los realistas estaban convencidos que los independentistas tenían unos 5000 hombres y se prepararon para darles el encuentro en las inmediaciones del Cerro Baúl que se encuentra en el camino entre Moquegua y Torata, desde donde se podía conectar fácilmente con Puno. García Camba deja en claro en sus memorias que la mayoría de los oficiales medios, así como toda la tropa eran «hijos del país» ${ }^{48}$. La estrategia era muy clara, dar batalla en el espacio donde tendrían más ventajas, utilizando el terreno y un gran número de espías para seguir el avance exacto del enemigo y asegurar la victoria. El día diecinueve de enero se llevó a cabo el encuentro en las inmediaciones del angosto valle de Torata, posicionado sus dos piezas de artillería sobre el Cerro Baúl. Si bien Valdés fue herido en la acción, la victoria fue claramente para los defensores de la corona y las tropas del ejército libertador del sur huyeron de manera desordenada a Moquegua donde se llevó a cabo un segundo encuentro el 21 de enero, que resultó en el absoluto desmembramiento del ejército libertador del sur que huyó como pudo por el Puerto de Ilo con dirección a Iquique ${ }^{49}$. En su carta describiendo el combate Alvarado deja en claro que la situación geográfica fue determinante ya que le dio ventaja a los realistas que tenían preparado el ataque con piezas de artillería, control sobre los estrechos valles que suben a la sierra, dejándoles tan solo el desierto ${ }^{50}$.

La derrota en estas dos batallas resultó en la completa destrucción del ejército construido con tanto esfuerzo y liquidó casi todos los batallones llegados desde el Río de la Plata, sus jefes se dispersaron y las tropas fueron donde pudieron. La mayoría de los chilenos optaron por abandonar el Perú para navegar al sur y contribuir con la campaña que se estaba organizando contra los últimos realistas en Valdivia. Solo algunos hombres volvieron a Lima a tratar de recomponer de alguna manera lo que se había logrado construir con tanto esfuerzo. Miller lamentó la absoluta destrucción de la Legión Peruana de la Guardia que había organizado con tanto esfuerzo e intentó de seguir hostilizando a Carratalá en la costa de Arequipa ${ }^{51}$. Las noticias de la derrota de la expedición no tardaron de esparcirse por todo el Perú, quedando en claro que el no haber aprovechado la posibilidad de marchar sobre la sierra central ante la ausencia de Canterac

\footnotetext{
${ }^{47}$ Mazzeo de Vivó, 2009, muestra la importancia de la región de Arequipa en este periodo.

${ }^{48}$ García Camba, 1846, vol. II: 38.

${ }^{49}$ Paz Soldán, 1868, vol. 2: 32.

${ }^{50}$ Oficio del General Rudencindo Alvarado, a bordo del Macedonia, 23 marzo 1823, en "Reimpresos de Campañas, acciones militares y conexas, 1823-1826", Colección Documental de la Independencia del Perú, 1971-76, Tomo VI. Asuntos Militares, vol. 9: 11.

${ }^{51}$ Miller, 1829: 19.
} 
había sido un error estratégico. El General victorioso volvió a Huancayo en febrero de 1823 con 1500 hombres que había tomado prisioneros en la campaña, algunos de los cuales lograron desertar y unirse a las guerrillas ${ }^{52}$. Las consecuencias de la pérdida del ejército en esta campaña a los Puertos Intermedios fueron mayores y una de ellas fue la inmediata caída del triunvirato.

\section{MAPA 1: PRIMERA CAMPAÑA A INTERMEdios}

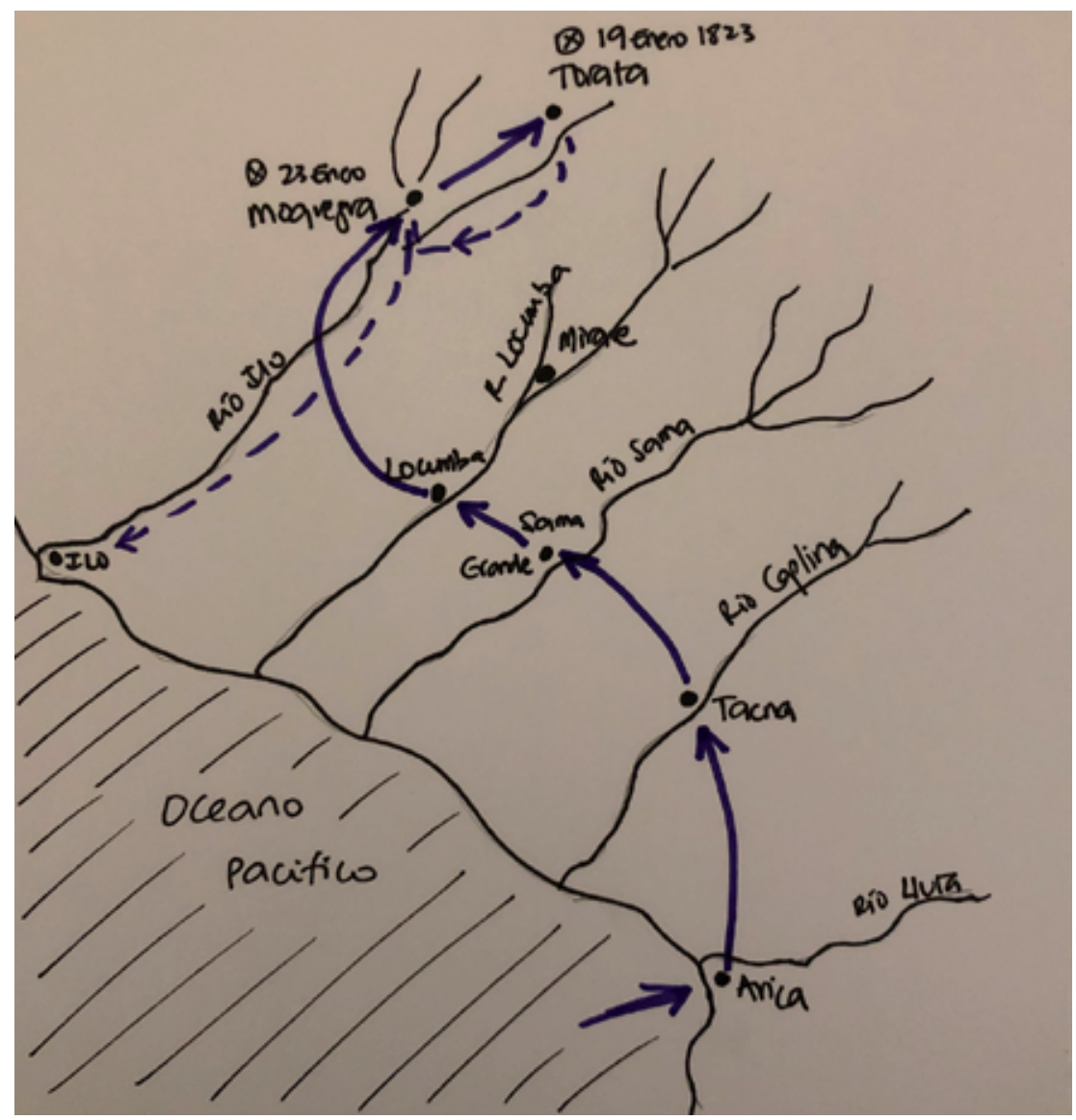

Fuente: elaboración propia.

52 Carta de Antonio Aliaga a Tomas Guido, Campamento de Quero 1 Marzo 1823, en "Guerrillas y montoneras durante la independencia", Colección Documental de la Independencia del Perú, 1971-76, tomo 5, vol. 4: 135. 
Al volver a Lima con los remanentes de las tropas Agustín Gamarra juntó fuerzas con Santa Cruz, su antiguo compañero de armas y el 26 de febrero desde el pueblo de Balconcillo, a las afueras de la capital, mandaron una representación al Congreso en nombre del Ejército Unido Libertador pidiéndole que se designara como presidente a José de la Riva Agüero ${ }^{53}$. El ultimátum militar venía acompañado de un memorial de los ciudadanos de Lima, firmado por Mariano Tramarria y una nota anónima de la Municipalidad de Lima pidiendo que se depusiera al triunvirato. Un día más tarde el Sub Inspector General de cívicos, el Conde de San Donás, escribió apoyando el pedido del ejército ${ }^{54}$. Algunos representantes como el clérigo Javier de Luna Pizarro se rehusaron a aceptar esta imposición, mientras que otros como el médico Hipólito Unanue buscó resolver el impase tratando de darle la presidencia a Torre Tagle, quien en ese momento tenía la colocación más alta que Riva Agüero en el ejército peruano. Tagle no estaba muy entusiasmando y Santa Cruz rechazó la propuesta amenazando con dejar la ciudad si no se respetaban los deseos del ejército ${ }^{55}$.

En realidad tanto Torre Tagle como Riva Agüero eran militares de salón y si bien tenían grados importantes y habían sido parte de la milicia desde su infancia no tenían un solo día de experiencia real de combate. Torre Tagle, quien ya era Gran Mariscal, juró en el cargo como primer presidente del Perú a Riva Agüero ${ }^{56}$. Santa Cruz y Gamarra querían que en el poder estuviera alguien en quien confiaban para poder organizar su campaña al sur, un espacio que ambos conocían bien y donde habían combatido por más de una década. Riva Agüero fue ascendido a Gran Mariscal y una de las primeras leyes que pasó fue para asegurarse que los milicianos sirvieran en el ejército y que decía «los soldados cívicos deben manifestar ser dignos de este nombre, presentándose a la instrucción militar tan necesaria para poder defender a su país con gloria y suceso ${ }^{57}$. El énfasis estaba en buscar una independencia por medio del sacrificio de los mismos peruanos, si bien se reconocía la importancia de la ayuda de los porteños y chilenos, además del apoyo de los colombianos a quienes se esperaba con ansias, el primer presidente peruano confiaba en la posibilidad de éxito de su estrategia y la de sus militares.

53 Sobrevilla Perea, 2012b: 268.

${ }^{54}$ Paniagua Corazao, 2003: 359.

55 Tagle, 1820.

${ }_{56}$ Nombramiento interino, 28 febrero 1823, en Colección Documental de la Independencia del Perú, 1971-76, Tomo VI Asuntos Militares, vol. 9: 18.

57 "Ley dada por Riva Agüero 1 marzo 1823", en Colección Documental de la Independencia del Perú, 1971-76, Tomo VI Asuntos Militares, vol. 9: 22. 
LA SEGUNDA CAMPAÑA A LOS PUERTOS INTERMEDIOS

Una de las cosas que facilitó la preparación de una nueva campaña tan poco tiempo después de haber perdido la anterior, fue la llegada del préstamo de Gran Bretaña negociado por García del Río y James Parosisien ${ }^{58}$. Esto le permitió a Riva Agüero recomponer la marina y a Santa Cruz y a Gamarra la posibilidad de convocar, vestir y armar a 5.000 hombres $^{59}$. A pesar de esto, en marzo Santa Cruz envió a algunos de los oficiales excedentes de los Dragones de San Martín y el de la Escolta a servir a las guerrillas de Canta aduciendo que había oficiales excedentes y que era necesario economizar ${ }^{60}$. El nuevo Presidente renegoció con Bolívar el acuerdo hecho con San Martín de enviar ayuda y a las pocas semanas llegó al Callao, Antonio José de Sucre con un contingente de 4.000 hombres, su misión no era puramente militar ya que se dedicó a preparar el camino para la llegada de Bolívar aprovechando cada falta de Riva Agüero ${ }^{61}$. El presidente buscó una tregua con el virrey, pero al no conseguirla declaró «guerra a muerte», inspirándose en la utilizada por Bolívar ${ }^{62}$. Buscaba que quienes continuaban apoyando a los realistas en muchas regiones del Perú dejaran de hacerlo, ya que sus ejércitos se componían, en su mayoría, de los llamados «hijos del país». Riva Agüero pensaba que al ser un presidente peruano, podría convencerlos de deponer las armas.

La estrategia militar puesta en marcha en la segunda campaña a intermedios fue similar a la llevada a cabo meses antes. Esta vez Sucre estaría a cargo de presionar sobre los Andes centrales al este de Lima y Santa Cruz y Gamarra llevarían sus tropas directamente al altiplano donde conocían muy bien el terreno y mantenían conexiones. Para ganar más apoyo movilizaron el lenguaje que idealizaba a los soldados como los salvadores de la nación. Un panfleto anunciaba, por ejemplo, que, «el soldado de la patria no necesita más que su bayoneta para triunfar y convertirse en poderoso» ${ }^{63}$. Antes de partir Santa Cruz fue nombrado general y en su discurso de despedida ante el Congreso en abril de 1823 declaró que derramaría hasta la última gota de sangre para lograr la victoria e imploró a Bolívar que vinie-

58 Miller, 1829: 56.

59 Sobrevilla Perea, 2015a: 88.

${ }^{60}$ Andrés de Santa Cruz a Don Ramón Herrera Ministro de Guerra, Miraflores 10 marzo 1823, "Guerrillas y montoneras durante la independencia", en Colección Documental de la Independencia del Perú, 1971-76, vol. IV: 152.

${ }_{61}$ Bulnes, 1897: 168, 177 y 181.

${ }^{62}$ Carta de Riva Agüero a La Serna y a Canterac, Lima 11 marzo, 1823, Colección Documental de la Independencia del Perú, 1971-76, Tomo VI Asuntos Militares, vol. 9: 25-33.

${ }_{63}$ Manifiesto imparcial..., 1823: 5. 
ra al Perú a salvarlo ${ }^{64}$. Tras la partida de Santa Cruz y Gamarra con un contingente muy grande de hombres, la situación en Lima era extremadamente delicada ya que la capital quedaba a merced de los colombianos. La situación, era aún más grave debido a la desarticulación de las guerrillas del centro que había coordinado el salteño Francisco de Paula Otero con mucho éxito. Este comerciante devenido en miliciano y luego en coronel, había logrado establecer una verdadera fuerza de choque en los valles al este de Lima asegurándose que las empinadas cordilleras que separan el valle del Mantaro de la costa fueran de difícil acceso a los realistas. Pero con la caída de la Junta en Lima fue reemplazado por un hombre que sus subalternos describían como «biejo rebiejo inutil inutilisimo [sic] $\rangle^{65}$. Si bien el cambio no duró mucho tiempo y Otero fue repuesto el control sobre la sierra central tardó en recuperarse.

Temeroso que Canterac, quien preparaba sus tropas en Huancayo, pudiera volver sobre Lima, Riva Agüero llamó en abril a que se elaborara una lista con todos los hombres hábiles para el servicio, con nombres y direcciones además de las armas de fuego e incluso cuchillos que pudieran tener. Quería saber también con cuantos esclavos podría contar para pelear. El recuento se llevó a cabo en todos los valles de Lima, tomando especial nota de los esclavos que todavía no eran parte de la milicia cívica ${ }^{66}$. Entre abril y mayo, Canterac y Riva Agüero intercambiaron correspondencia cada vez menos cordial, dejando en claro que el ataque del así llamado Ejército Nacional sobre Lima se hacía inevitable. Bolívar demoraba su salida de Guayaquil, arguyendo que no podía hacer nada sin el permiso del Congreso de Colombia, pero quedaba claro que no quería intervenir por temor a que el sur fuera liberado antes de su llegada ${ }^{67}$. Sucre se presentó ante el Congreso Peruano el 23 de mayo de 1823, diciendo «que la división auxiliar colombiana ofrece sus armas a la Representación nacional por garantía de su libertad; y que se honrará en servirle tan celosa y fielmente como soldados peruanos $\rangle^{68}$. A pesar del lenguaje florido y las aparentes buenas intenciones, Sucre temía que la falta de cohesión entre las fuerzas de distintos orígenes estacionadas en Lima, era un problema

${ }^{64}$ Sobrevilla Perea, 2015a: 89.

${ }^{65}$ Carta de Joaquín Daubosa a Espinar, Huanuco 29 de marzo 1823, "Guerrillas y montoneras durante la independencia", en Colección Documental de la Independencia del Perú, 1971-76, vol. IV: 200.

66 José de la Riva Agüero, Bando. El Presidente de la República Peruana. Por cuanto conviene al poder que administro, Lima, 25 abril 1823, Biblioteca de la Universidad de Yale.

${ }^{67}$ Carta de Antonio José de Sucre a Simón Bolívar, Lima 10 mayo 1823, en O’Leary, 1919: 45.

${ }^{68}$ Oficio del General Sucre al Congreso Peruano, 23 mayo 1823, en Colección Documental de la Independencia del Perú, 1971-76, Tomo VI Asuntos Militares, vol. 9: 52. 
tan grave que solo la presencia de Bolívar podría solucionar ${ }^{69}$. Pero el Libertador estaba ocupado pensando en las implicancias geopolíticas a largo plazo y buscando consolidar la agregación de Guayaquil a Colombia, algo que no todos aceptaban. Dado que el Reino de Quito había buscado autonomía desde 1809, incluso su incorporación a Colombia resultaba problemática. La posibilidad que la Audiencia de Charcas se independizara sin su participación y se disgregara de lo que había sido el Virreinato del Río de la Plata preocupaba a Bolívar. Pero lo que más temía era perder su ejército de hombres altamente entrenados en una batalla que podría no ganar $^{70}$.

La expedición al sur comenzó con muy buenos resultados, una partida inutilizó al enemigo en el valle de Azapa facilitando la subida a Oruro. Algunos de los soldados que habían sido tomados en Moquegua desertaron y se unieron a las filas recién llegadas de Lima. Mientras que el desembarco en Arica y la marcha a Tacna se dieron sin contratiempos ${ }^{71}$. A diferencia de la situación vivida seis meses antes, el camino se encontraba libre, Canterac se preparaba a tomar Lima y ni Valdés ni Carratalá habían dejado sus posiciones en Arequipa y Ayacucho. En ese momento la consigna era tomar Lima, así fue que, el 18 de junio 9000 tropas veteranas, nueve batallones y nueve escuadrones bien armados y uniformados bajaron de la sierra con rumbo a La Capital, acompañadas de catorce piezas de artillería ${ }^{72}$. Según la información de las guerrillas estacionadas en la zona, solamente unos 1000 de estos eran europeos, el resto eran reclutas americanos incluyendo por lo menos 700 morenos de Arequipa y 500 indios de $\mathrm{La} \mathrm{Paz}^{73}$. El Congreso cesó a Riva Agüero de la presidencia poniéndola al mando de Sucre ${ }^{74}$. El noble limeño, sin embargo, no acató el pedido y navegó a Trujillo donde eventualmente estableció otra sede de gobierno con algunos de los parlamentarios. En Lima unas 10.000 personas, temerosas ante la llegada de los realistas, buscaron refugio en el Callao. La ocupación de Canterac, que fue acompañada de pedidos de cupos, duró el mes de julio de $1823^{75}$. En agosto, después de la partida de los realistas, lo que quedaba del Congreso

\footnotetext{
${ }^{69}$ Carta de Sucre a Bolívar, Lima, 10 mayo 1823, en O’Leary, 1919: 45.

${ }^{70}$ Carta de Bolívar a Sucre, Guayaquil, 25 mayo 1823, en Archivo Bolívar, Caracas, doc. 7442 .

${ }^{71}$ Boletín n. ${ }^{\circ} 1$ del Ejército Expedicionario Libertador del Sur, en Colección Documental de la Independencia del Perú, 1971-76, Tomo VI Asuntos Militares, vol. 9: 57-59.

72 Miller, 1829: 58.

${ }^{73}$ Manuscrito 1815 de la Biblioteca Nacional, "Guerrillas y montoneras durante la independencia”, en Colección Documental de la Independencia del Perú, 1971-76, tomo 5, vol. IV: 440-441.

${ }^{74}$ Hernández García, 2019: 125.

75 Sobrevilla Perea, 2015b: 90-91.
} 
en Lima nombró presidente a Torre Tagle mientras que Sucre se preparó a marchar al sur a apoyar la campaña de Santa Cruz, con tres mil hombres, entre colombianos, chilenos y peruanos ${ }^{76}$.

La ocupación de Lima le dio a Santa Cruz y Gamarra una ventaja ya que pudieron avanzar sin impedimento sobre el altiplano. En junio tenían a 3.000 hombres acantonados en Moquegua y el 23 de ese mes dividieron las tropas por mitad, Gamarra se dirigió a Oruro por el camino de Tacna y Santa Cruz a Puno y por el Desaguadero hasta La Paz que ante la retirada de la guarnición realista ocupó sin problema el 7 de agosto ${ }^{77}$. Pardo de Zela, por otra parte, se dirigió a las costas de Arequipa para intentar detener las fuerzas de Carratalá, quien gracias a los refuerzos desde el Cuzco, contaba con mil quinientos hombres listos para maniobrar ${ }^{78}$. Gamarra entró en Oruro el 10 de agosto habiendo obligado a Olañeta a evacuar con rumbo a Potosí con sus 1.500 hombres, y a dejar armamento y piezas de artillería en manos de los patriotas. La retirada también se debía a que la retaguardia se veía amenazada por Arenales quien había llegado a las provincias del norte argentino a maniobrar sobre Salta, Tucumán y Santiago ${ }^{79}$. Ante la avanzada del ejército libertador del sur comandado por los generales peruanos, el Comandante Lanza que había mantenido una de las llamadas Republiquetas independientes en la Audiencia de Charcas, por más de seis años se acercó a reforzar a Gamarra con sus hombres ${ }^{80}$. Santa Cruz había logrado de esta manera cortar la comunicación del Cuzco con las provincias de la Audiencia de Charcas y esperaba poder hacer lo mismo con Arequipa dado que Sucre se estaba embarcando desde Lima para dar apoyo a Pardo de Zela y Canterac se veía obligado a abandonar la capital y volver a la sierra ${ }^{81}$.

A mediados de agosto la situación del ejército libertador del sur era poderosa y contaba con casi 7000 hombres entre La Paz y Oruro ${ }^{82}$. Valdés

${ }^{76}$ Nombramiento de Jefe Supremo Político y Militar, "S.E. el Gran Mariscal Don José Bernardo Tagle", en Colección Documental de la Independencia del Perú, 1971-76, Tomo VI Asuntos Militares, vol. 9: 67.

77 Miller, 1829: 62.

${ }^{78}$ Extractos de las noticias traídas por el transporte Bombona procedente de Arica, Lima, 10 de agosto 1823, en Colección Documental de la Independencia del Perú, 1971-76, Tomo VI Asuntos Militares, vol. 9: 69.

${ }^{79}$ Carta de Pedro Antonio de Olañeta a José de la Serna, Viacha, 14 agosto 1823, en Colección Documental de la Independencia del Perú, 1971-76, Tomo VI Asuntos Militares, vol. 9: 79 .

${ }^{80}$ Miller, 1929: 62.

${ }^{81}$ Gaceta n. $^{\circ} 1$ del Ejército Libertador del Sur, Boletín n. ${ }^{\circ}$ 3, en Colección Documental de la Independencia del Perú, 1971-76, Tomo VI Asuntos Militares, vol. 9: 74.

${ }^{82}$ García Camba, 1846, vol. II: 67. 
avanzó sobre Puno con un escuadrón a las orillas del Lago Titicaca, muy cerca donde se había dado la victoria de Goyeneche en Guaqui en 1811, cuando Santa Cruz y Gamarra comenzaban su carrera militar ${ }^{83}$. Carratalá lo apoyó con sus tropas estacionadas en Arequipa, dejando la retaguardia en la ciudad para enfrentar la llegada de Sucre con 3.000 hombres entre colombianos, chilenos y peruanos ${ }^{84}$. Valdés quien no esperaba tanta determinación por parte de Santa Cruz avanzó sobre el punto de Zepita con unos 1.800 hombres y cuatro piezas de artillería el 25 de agosto. Ese día se dio la batalla y Santa Cruz, que contaba con unos 1600 hombres los derrotó dejando unos 1.200 hombres entre muertos, heridos y prisioneros en el campo de batalla ${ }^{85}$. Canterac avanzó con su división por la sierra central hasta el Cuzco dejando al coronel Loriga en la retaguardia, pero llegó a Puno después de la derrota ${ }^{86}$. Para el primero de septiembre Sucre ocupaba Arequipa con tropas veteranas que incluían a Miller mientras que Santa Cruz se había retirado sobre el Desaguadero donde creía poder mantener el control de la entrada a la Audiencia de Charcas al tener el dominio del Puente Inca. Canterac decidió maniobrar por Haumanga para presionar a Sucre, mientras que desde el Cuzco, el virrey La Serna bordeó el lago Titicaca con unos 4000 hombres, sorprendiendo a Santa Cruz con su velocidad y pericia ${ }^{87}$. Sin muchas opciones, el ejército libertador del sur se replegó a Oruro con la intención de unirse a las tropas de Gamarra y enfrentar a La Serna. Pero el virrey, ahora con una tropa muy superior, decidió no dar batalla hasta reunirse con la división de Olañeta que avanzaba rápidamente con 2500 hombres de refuerzo ${ }^{88}$. Ante esos números Santa Cruz y sin tiempo para esperar el posible apoyo de Arenales desde Salta, o de Sucre desde Arequipa, la única opción era abandonar todo el terreno ganado y replegarse por el Puente Inca del Desaguadero con la esperanza de volver a la costa ${ }^{89}$.

Una vez más todo el ejército libertador del sur fue completamente destruido y la segunda campaña de intermedios terminó en una derrota absoluta. A pesar de haber logrado dividir las fuerzas de los realistas con Canterac en Lima y Olañeta en el sur de la Audiencia de Charcas defendiéndose de Arenales, Valdés y Carratalá siguieron firmes y el virrey mostró su capacidad al

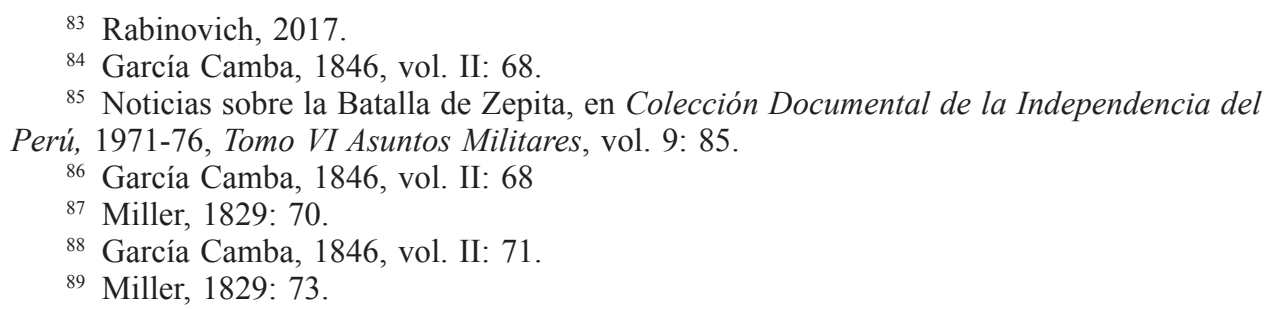


maniobrar de tal forma que Santa Cruz y Gamarra quedaron sin posibilidades. Si bien Sucre se encontraba en Arequipa, su correspondencia con Bolívar muestra que no tenía intenciones de servir bajo el comando de Santa Cruz ${ }^{90}$. A fines de octubre se encontraron entre Tacna y Arica los dispersos que venían del altiplano, con los refuerzos recién llegados de Chile, que al ver la situación desesperada del ejército libertador se dividieron entre los pocos que siguieron viaje a Lima y la mayoría que regresó a Valparaíso a seguir la campaña contra los realistas en Valdivia ${ }^{91}$. Santa Cruz se embarcó en el O'Higgings donde el almirante Guisse le dio la bienvenida y enrumbó a Lima ${ }^{92}$. En Arequipa el virrey nombró a Canterac general en jefe del ejército del norte y a Valdés del sur, reorganizando todas sus fuerzas después de la victoria absoluta ${ }^{93}$. La situación después de todos los esfuerzos hechos durante el año 1823, era prácticamente la misma que un año antes, la única esperanza que mantenían era el apoyo de Bolívar.

\section{LAS CONSECUENCIAS DE LAS CAMPAÑAS A INTERMEDIOS}

La absoluta derrota de quienes buscaban la independencia en estas dos ocasiones dejó en claro que la capacidad de quienes luchaban por la corona era muy superior y que su control de los Andes sur, desde el valle del Mantaro hasta Salta era absoluto. En el norte, donde la independencia se había jurado dos años antes, reinaba la desunión más grande con dos gobiernos enfrentados, uno con capital en Lima y el otro en Trujillo. Bolívar había llegado finalmente al Perú mientras Santa Cruz y Gamarra luchaban en campaña contra Canterac, Olañeta y La Serna; y Sucre esperaba en Arequipa. El tres de septiembre de 1823 el Libertador desembarcó en el Callao y declaró poco después ante el Congreso que había abandonado Colombia huyendo del ejercicio del poder civil, ya que lo único que buscaba era «usar su espada para la salvación de la patria» y encargó a los representantes que se dedicaran a terminar de escribir su constitución ${ }^{94}$. Torre Tagle, que había quedado encargado del poder ejecutivo en Lima, dio un paso al costado y el Congreso nombró a Bolívar, dictador ${ }^{95}$. Mientras tanto en el norte, en Trujillo, Riva

\footnotetext{
${ }^{90}$ Carta de Sucre a Bolívar, Arequipa, 7 de septiembre 1823, en O’Leary, 1919: 112-116.

91 Sobrevilla Perea, 2015b: 95.

92 Miller, 1829: 74.

93 García Camba, 1846, vol. II: 78.

${ }^{94}$ Carta de Simón Bolívar al Congreso Peruano, 5 septiembre 1823, Archivo del Libertador, Caracas, doc. 7744

95 Miller, 1829: 89.
} 
Agüero había disuelto el Congreso a mediados de julio y gobernaba con un pequeño senado mientras mantenía la esperanza que una victoria de Santa Cruz le fuera favorable y que con ella podría lograr la independencia sin el apoyo de los colombianos ${ }^{96}$. En estos meses, e inspirado por el compromiso que se había llegado en México con la corona, Riva Agüero entró en negociaciones con los realistas, pensando en la posibilidad de llegar a un acuerdo como el que se había conseguido por Buenos Aires ${ }^{97}$. En su carta al virrey, Riva Agüero habla de poner fin a «esta plaga terrible que nos devora» en el «día feliz de nuestra reconciliación», algo que muchos autores han identificado como una voluntad de establecer una monarquía constitucional y que al caer en manos de Bolívar fue el detonante para que fuera depuesto ${ }^{98}$.

Pero para octubre de 1823, Santa Cruz se encontraba derrotado y camino a Lima. Sucre había abandonado Arequipa y navegaba desde el puerto de Quilca a la capital, donde Bolívar era ya dictador. Los realistas que dominaban la sierra desde el centro tenían la esperanza de aliarse con Riva Agüero, pero al final después de muchas tratativas este no aceptó sus propuestas ${ }^{99}$. Un mes más tarde el Congreso en Lima dio la primera constitución peruana, que si bien era abiertamente liberal, nunca se llegó a poner en práctica ya que Bolívar gobernaba como dictador y su interés mayor era terminar con el gobierno de Riva Agüero para poder enfrentarse a los realistas ${ }^{100}$. Según García Camba el retorno de las tropas del sur en estado deplorable, no hizo más que fomentar «las notorias rivalidades existentes entre los diversos pabellones independientes que existían en Lima» ${ }^{101}$. No le faltaba razón al coronel realista, ya que la situación a fines de 1823 era aún menos propicia para los independentistas que las de un año antes. Sin ningún auxilio del Río de la Plata, donde no existía un gobierno centralizado, y solo algunos hombres rezagados de esas provincias aún en el Perú, y con cada vez menos apoyo de Chile que se encontraba buscando su propio arreglo constitucional además de peleando contra los realistas en el sur, todo el socorro venía de Bolívar y los colombianos. Los peruanos por otra parte, estaban profundamente divididos y fue uno de ellos, Antonio Gutiérrez de la Fuente quien depuso a Riva Agüero, buscando de esta manera garantizar que los colombianos se mantuviesen en el Perú.

\footnotetext{
96 Hernández García, 2019: 129-132.

97 Ibidem: 152.

98 San Martín, 2020: 44 y 45.

99 García Camba, 1846, vol. II: 80.

${ }^{100}$ Miller, 1829: 89

101 García Camba, 1846, vol. II: 83.
} 
El año 1823 y las campañas a los puertos intermedios fueron el momento en el que los jefes peruanos hubieran podido lograr la independencia. La consecuencia de corto plazo de esta derrota fue que al no lograr hacerlo, el fin de la guerra hubo de depender necesariamente del apoyo externo. En todo caso, las campañas fueron posibles gracias a las fuerzas de muchas regiones de América en colaboración y los problemas que tuvieron se debieron en gran parte a las divisiones entre quienes buscaban obtener la independencia. Por un lado, los jefes llegados desde el Río de la Plata tenían cada vez menos incentivos para participar, fue por ello que alguno de los más experimentados, como Juan Antonio Álvarez de Arenales, se decidió a volver a Salta. Otros como Francisco de Paula Otero y Tomás Guido se mantuvieron en el Perú, pero no participaron en las campañas en el sur y se quedaron en la sierra central y Lima respectivamente. Rudencindo Alvarado, aún después de su derrota en la primera campaña se quedó en el Perú, como gobernador del Callao, ya que la situación en el Río de la Plata no era precisamente la más atractiva. Así como algunos oficiales no volvieron las posibilidades para los hombres de menor rango eran mínimas. El apoyo de Chile se mantuvo aún después de la debacle de la primera campaña, pero sus refuerzos para la segunda campaña llegaron tarde y no fue mucho lo que lograron colaborar ya que la situación en el sur era cada vez más compleja.

Una consecuencia de mediano plazo, fue que las derrotas marcaron el inicio de la participación de los colombianos en la independencia peruana, que fue determinante el año siguiente. Pero en 1823 no quedaba tan claro como se iban a organizar los nuevos estados y los generales Paz del Castillo, Sucre y Bolívar querían primero asegurar que el puerto de Guayaquil y los territorios de la Audiencia de Quito se incorporaran a Colombia. Bolívar no veía con buenos ojos la posibilidad que la Audiencia de Charcas dejara de ser parte del territorio del estado sucesor al Virreinato del Río de la Plata, ya que eso le podría traer problemas más al norte. Desconfiaba entonces de la opción de que estos espacios se independizaran ya que era perfectamente posible imaginar un nuevo estado que cubriera la Audiencia de Charcas y bajara por el altiplano al oeste hasta llegar al Pacifico. Pero la división entre los mismos peruanos tampoco ayudó a que la independencia fuera posible en este momento. La creación de dos gobiernos independientes paralelos, uno en Lima y otro en Trujillo, no hizo más que hacer que la situación fuera aún más compleja. Lo que queda claro es que en este momento quienes luchaban por mantener el control de la corona española en el Perú se conservaban unidos y tenían el apoyo de muchas personas en las zonas sur andinas. Es indudable que contaban con una serie de oficiales altamente experimentados, muchos de ellos veteranos de las guerras napoleónicas en la península, pero ellos eran la 
minoría, y la mayor parte de las personas que hicieron posibles sus victorias fueron los que un número importante de los que se llamaban «hijos del país» y que seguían convencidos que la mejor opción era mantenerse fieles al rey y a la constitución. A largo plazo la derrota de los Puertos Intermedios significó que una posible unión entre los territorios de la Audiencia de Charcas y los del Perú, como la había imaginado Santa Cruz, se hizo imposible y las fronteras se trazaron de la forma en que las conocemos ahora. Para entender el proceso de la independencia peruana es necesario alejarse de las nociones de que los peruanos lucharon por su independencia, o no, y más bien revisitar los procesos particulares que se llevaron a cabo, además de la actuación de los múltiples actores de orígenes variados. La independencia peruana estuvo íntimamente ligada a la del resto del continente y los estados que surgieron de las guerras necesitaron por lo menos un par de décadas para comenzar a consolidarse.

\section{BiBLIOGRAFÍA}

Bonilla, Heraclio y Spalding, Karen, "La independencia: las palabras y los hechos", Heraclio Bonilla (ed.), La independencia en el Perú, Lima, Instituto de Estudios Peruanos, 1971.

Bulnes, Gonzalo, Las últimas campañas de la independencia del Perú (1822-1826), Santiago de Chile, Imprenta Barcelona, 1897.

Colección Documental de la Independencia del Perú, Lima, Comisión nacional del Sesquicentenario de la independencia, 1971-1976, 86 vols.

De la Puente y Candamo, José, La Independencia del Perú, Lima, Fondo Editorial del Congreso Peruano, 2013.

García Camba, Andrés, Memorias del General García Camba para la historia de las armas españolas en el Perú, Madrid, Tipografía Benito del Hortelano y compañía, 1846.

García Camba, Andrés, Memorias del General García Camba para la historia de las armas españolas en el Perú, Madrid, Editorial Americana, 1916.

Hernández García, Elizabeth, José de la Riva Agüero y Sánchez Boquete (1783-1858) Primer Presidente del Perú, Lima, Fondo Editorial del Congreso del Perú/Instituto Riva Agüero, 2019.

Lynch, John, Simón Bolivar: a life, New Haven, Yale University Press, 2006.

Lynch, John, José de San Martín: Argentine Soldier, American Hero, New Haven, Yale University Press, 2009. 
Manifiesto imparcial de los acontecimientos de la capital del Perú desde la salida del Ejército expedicionario para los Puertos Intermedios hasta el fin de marzo del presente año, Lima, Imprenta Masías, 1823.

Martínez Riaza, Ascensión, "Todos eran realistas. Liberalismo y absolutismo en el gobierno del Virreinato del Perú, 1820-1824”, Izaskun Álvarez Cuartero y Julio Sánchez Gómez (eds.), Visiones y revisiones de la independencia americana: realismo, pensamiento conservador: ¿una identificación equivocada?, Salamanca, Ediciones Universidad de Salamanca, 2014: 121-144.

Mazzeo de Vivó, Cristina, "Los nudos de la desunión: Conflictos y Divergencia del Ejército Realista durante la Emancipación del Perú 1810-1824”, Revista de Indias, LXIX/247 (Madrid, 2009): 105-126.

McEvoy, Carmen, "El Motín de las palabras: la caída de Bernardo de Monteagudo y la forja de la cultura política Limeña (1821-1822)", Boletín del Instituto Riva Agüero, 23 (Lima, 1996): 89-139.

Miller, John, Memorias del General Guillermo Miller al Servicio del Peru, Madrid, Librería Victoriano Suarez, 1829, vol. 2.

O’Leary, Daniel Florence, Cartas de Sucre al Libertador (1820-1826), Madrid, Editorial América, 1919.

Ortemberg, Pablo, Rituales de poder en Lima 1735-1828, Lima, Pontificia Universidad Católica del Perú, 2014.

Ortiz de Zevallos, Javier, San Martín y Torre Tagle en la Independencia del Perú, Lima, Centro de Documentación e Información Andina, 1987.

Ossa Santa Cruz, Juan Luis, Armies, Politics and Revolution, Liverpool, Liverpool University Press, 2014.

Paniagua Corazao, Valentín, Los orígenes del Gobierno Representativo en el Perú. Las elecciones (1809-1826), Lima, PUCP/FCE, 2003.

Paz Soldán, Marino Felipe, Historia de Perú Independiente, Segundo Periodo, Lima, Imprenta de la Escuela de Ingenieros, 1868.

Peralta Ruíz, Víctor, "La restauración absolutista y la cultura política en el gobierno del virrey Pezuela", La independencia y la cultura política peruana (1808-1821), Lima, Instituto de Estudios Peruanos, 2010: 273-307.

Pezuela, Joaquín de la, Memoria de Gobierno del virrey Pezuela, Sevilla, Escuela de Estudios Hispanoamericanos, 1947.

Rabinovich, Alejandro, "La máquina de la guerra y el Estado: el Ejército de los Andes tras la caída del Estado central del Río de la Plata en 1820”, Juan Carlos Garavaglia, Juan Pro Ruiz y Eduardo Zimmermann (eds.), Las fuerzas de Guerra en la construcción del Estado en América Latina, siglo XIX, Rosario, Prohistoria, 2012: 205-241. 
Rabinovich Alejandro, Anatomía del pánico. La Batalla de Huaqui, Buenos Aires, Siglo XXI, 2017.

Refutación que hace el Mariscal de Campo don Jerónimo Valdés al Manifiesto que el Teniente General don Joaquín de la Pezuela imprimió en 1821 a su regreso al Perú y que imprime su hijo el Conde de Torata, coronel retirado de artillería, Madrid, Imprenta de la viuda de Minuesa de los Rios, 1895, tomo II.

Sala i Vila, Nuria, "El Trienio Liberal en el Virreinato peruano: los ayuntamientos constitucionales de Arequipa, Cusco y Huamanga, 1820-1824", Revista de Indias, 71/253 (Madrid, 2011): 693-728.

San Martín Vásquez, Juan Alberto, "La participación de José de la Riva Agüero y Sánchez Boquete en el proceso de independencia del Perú vista a través de sus memorias", Desde el Sur, 12/1 (Lima, 2020): 37-55.

Sobrevilla Perea, Natalia, "Estudio introductorio", Compendio de los Sucesos Ocurridos en el Ejército del Perú y sus Provincias (1813-1816) de Joaquín de la Pezuela, Natalia Sobrevilla y Pablo Ortemberg (eds.), Santiago, Instituto de Estudios Bicentenario, 2011a: XI-XXXIX.

Sobrevilla Perea, Natalia, "From Europe to America and Back, becoming "Los Ayacuchos», European Historical Quarterly, 41/3 (Londres, 2011b): 472-488.

Sobrevilla Perea, Natalia, "Luchando por «la patria» en los Andes, 1808-1815", Revista Andina, 52 (Ciudad, 2012a): 61-83.

Sobrevilla Perea, Natalia, "De vasallos a ciudadanos: las milicias coloniales y su transformación en un ejército nacional en las guerras de independencia en el Perú", Carmen McEvoy y Elias Palti (eds.), Independencia y Democracia, Lima, Editorial Bicentenario, 2012b: 251-270.

Sobrevilla Perea, Natalia, "Entre proclamas, actas y una capitulación: la independencia peruana vista desde sus actos de fundación", Alfredo Ávila, Jordana Dym y Erika Pani (eds.), Las Declaraciones de Independencia Los Textos Fundamentales de las Independencias Americanas, México, El Colegio de México, 2013: 241-274.

Sobrevilla Perea, Natalia, "La nación subyacente: de la monarquía hispánica a la creación del Estado en el Perú", Carlos Contreras y Luis Miguel Glave (eds.), La independencia del Perú ¿Concedida, Conseguida, Concebida?, Lima, Instituto de Estudios Peruanos, 2015a.

Sobrevilla Perea, Natalia, Andrés de Santa Cruz, el caudillo de los Andes, Lima, Instituto de Estudios Peruanos, 2015b.

Sobrevilla Perea, Natalia, "La participación británica en las Guerras de Independencia", Mauricio Novoa, Perú \& Gran Bretaña: Una historia en común, Lima, Instituto Británico, 2018: 14-43.

Sosa Abela, Guillermo, "los ciudadanos en la constitución de Cucutá", Anuario Colombiano de Historia Social y de la Cultura, 31/1 (Bogotá, 2009): 56-88. 
Subrahmanyam, Sanjay, Explorations in Connected History from the Tagus to the Ganges, Dehli, Oxford University Press, 2004.

Subrahmanyam, Sanjay, Explorations in Connected History: Mughals and Franks, Dehli, Oxford University Press, 2009.

Tagle, José Bernardo de, Narración que hace de sus servicios a la causa de América, Lima, Imprenta del Gobierno, 1820.

Fecha de recepción: 8 de enero de 2020 .

Fecha de aceptación: 20 de agosto de 2020.

\section{The intermediate port campaigns and the "Peruvian" phase of independence}

Even though Peruvian historiography has devoted little attention to the campaigns at what are known as the intermediate ports, located between Callao and Valparaiso, these marked one of the most important moments of the so-called "Peruvian" independence phase, even though both ended in defeat. The campaigns deserve more academic attention, firstly because they are where most Peruvians were involved; secondly because, had they been successful, they would have resulted in very different states from those that exist today in this region of the continent; and thirdly because the problems that surfaced during these campaigns highlighted the difficulties the new emerging states would face.

KeY WORDs: wars of independence; intermediate ports campaign; Peruvian independence. 
